NOTES FROM THE LAB

\title{
Dengue Tests: What, When, and How?
}

\author{
Malavalli V Bhavana \\ Pediatric Infectious Disease (2020): 10.5005/jp-journals-10081-1276
}

The monsoons bring with them a fresh wave of dengue cases every year. Efficient and accurate diagnosis of dengue is of primary importance for clinical care. This article is an attempt to showcase the tests available for this illness and a rational way of using these tests.

Dengue virus is a spherical, enveloped, single-stranded RNA virus belonging to the flavivirus family. There are four serotypes: DEN-1, 2, 3, and 4. The important viral proteins include three structural and seven nonstructural proteins. The structural proteins are capsid (C), membrane (M), and envelope (E). Nonstructural (NS) proteins are NS-1, 2A, 2B, $-3,-4 \mathrm{~A},-4 \mathrm{~B}$, and -5 . Particularly, NS1 antigen is glycoprotein that is synthesized by all flaviviruses and secreted from infected mammalian cells during the acute phase of infection. $^{1-3}$

Illness begins 5-7 days after the infected mosquito bite. Viremia peaks during the first 2 to 3 days of acute illness and then declines sharply. The major host cell targets are monocytes, macrophages, and dendritic cells. This has an impact on immune modulation. ${ }^{1,2}$

Understanding the immune response to the virus is very important. In primary dengue, detectable NS1 antigen and viremia happens between 1 and 5 days. Immunoglobulin $\mathrm{M}$ (IgM) antibodies are detectable in $50 \%$ of patients by days 3 to 5 , increasing to $80 \%$ by day 5 and $99 \%$ by day 10 . It declines to undetectable levels over 2 to 3 months. Immunoglobulin G (IgG) antibodies are detectable at low titers at the end of the first week of illness, increasing slowly thereafter, with serum IgG still detectable after several months and probably even for life. In secondary dengue, the antibody titers rise rapidly and react broadly against many flaviviruses. The primary antibody is lgG which is detectable at high levels, even in the acute phase, and persists for 10 months to life. Early convalescent stage IgM levels are significantly lower in secondary infections than in primary ones and may be undetectable in some cases, depending on the test used. It is to be noted that primary infection results in noncomplicated dengue fever and the development of both humoral and cellular immunity (Fig. 1). It does not confer long-term cross-protection to other serotypes. Antibodies from a previous exposure mediate an enhancement of infection to subsequent heterologous serotypes. This phenomenon is known as antibodydependent enhancement. ${ }^{4-6}$

Laboratory diagnosis includes specific and non-specific tests. Specific tests comprise of detection of the virus or viral nucleic acid, detection of antigens or antibodies, or a combination of both.

The most frequently used test is the dengue enzyme-linked immunosorbent assay (ELISA). It is important to know in which stage of infection what test needs to be asked for. NS1, IgM, and IgG can be detected by ELISA. NS1 antigen is to be done in less than 5 days of fever. IgM can be detected 3-days after the onset of fever and persist for 30-90 days. IgG differs in primary and secondary presentations of dengue. In secondary infection, high levels of IgG are present 1-2 days after the onset of infection that may be accompanied by elevated IgM levels.
Department of Microbiology, Manipal Hospital, Bengaluru, Karnataka, India

Corresponding Author: Malavalli V Bhavana, Department of Microbiology, Manipal Hospital, Bengaluru, Karnataka, India, e-mail: bhavana224@gmail.com

How to cite this article: Bhavana MV. Dengue Tests: What, When, and How? Pediatr Inf Dis 2020;2(3):118-119.

Source of support: Nil

Conflict of interest: None

It is very important to remember that a negative test does not exclude dengue infection; re-test may be needed in 3-4 days if dengue is strongly suspected.

An ELISA report needs to be interpreted carefully. The various scenarios have been elucidated in Table 1.

Cross-reactivity of IgM antibodies has been observed for malaria, rheumatoid factor, and other flaviviruses. Results of IgG from immunosuppressed patients must be interpreted with caution.

Analysis of paired serum samples from acute and convalescent phases should be performed in order to provide confirmation of results. IgM-lgG ratio is often used to discriminate primary and

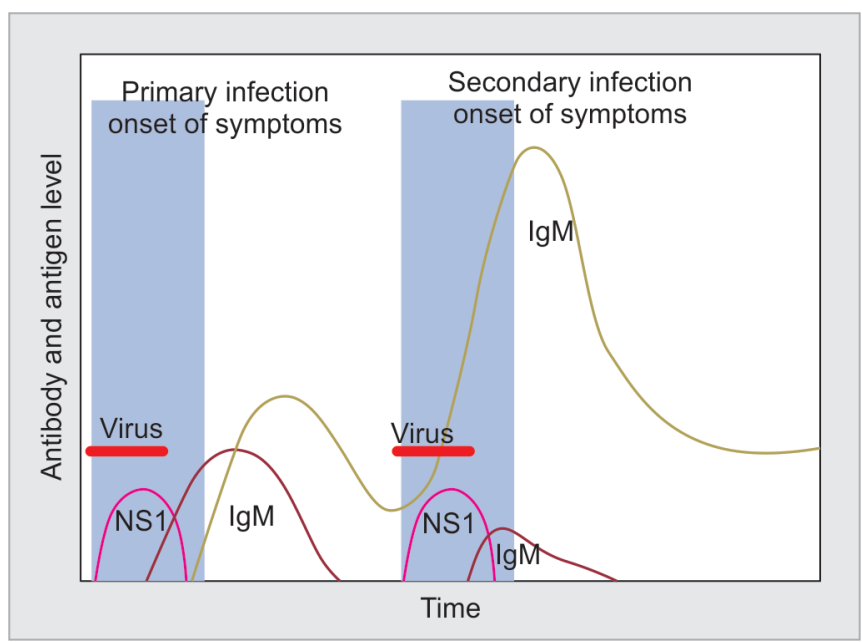

Fig. 1: Immune response to dengue

Table 1: Interpreting ELISA report

\begin{tabular}{ll}
\hline NS1 positive & Primary dengue infection \\
NS1 and IgM positive & Primary dengue infection \\
IgM and IgG positive & Secondary dengue infection \\
IgG positive & Secondary dengue infection \\
Only lgM positive & Rule out cross-reactivity \\
\hline
\end{tabular}

(0) The Author(s). 2020 Open Access This article is distributed under the terms of the Creative Commons Attribution 4.0 International License (https://creativecommons. org/licenses/by-nc/4.0/), which permits unrestricted use, distribution, and non-commercial reproduction in any medium, provided you give appropriate credit to the original author(s) and the source, provide a link to the Creative Commons license, and indicate if changes were made. The Creative Commons Public Domain Dedication waiver (http://creativecommons.org/publicdomain/zero/1.0/) applies to the data made available in this article, unless otherwise stated. 
secondary dengue infection. If the ratio of $\lg M$ to $\lg G$, as measured by titer, is more than 1.2, it indicates primary infection, and if the ratio is less than 1.2 , it indicates secondary infection. ${ }^{5,7}$

Rapid tests using immunochromatography are less sensitive and specific. The results are to be confirmed by ELISA.

Among the molecular methods, we have the real-time reverse transcriptase polymerase chain reaction (PCR). It is recommended in the acute phase. This test is $80-90 \%$ sensitive and $95 \%$ specific. A positive PCR result is a definite proof of current infection and it usually confirms the infecting serotype. Negative result is interpreted as "indeterminate", and a retest is done on second serum sample for serological confirmation after the fifth day of illness. The other serological tests, rarely done, are hemagglutination inhibition test (HI) and plaque reduction neutralization test (PRNT). There are ongoing studies on IgA ELISA, which is deemed to be noninvasive. ${ }^{8}$

Virus isolation/culture is done in only in research settings. It can be done with plasma, serum, peripheral blood, cerebrospinal fluid, pleural fluid, and immune system tissues, within 5 days of infection. Inoculation of specimens is done into mosquitoes, in vitro cultured cell lines, or intracerebrally in mice. Growth of the virus is confirmed by detection of antigen in the brain of the animals by serotype-specific immunofluorescence. It is a cumbersome, lengthy procedure. It is also not possible to differentiate between primary and secondary infection. ${ }^{8}$

The nonspecific tests that aid in the diagnosis and monitoring include complete blood count, platelet count, immature platelet factor (IPF), hematocrit, PT/aPTT, liver function tests, and serum albumin.

Laboratory tests form a significant part of clinical management of dengue. The points to be always remembered with respect to the dengue diagnostic tests are:
- No role of rapid tests, result always to be confirmed with ELISA.

- A negative report does not rule out the possibility of dengue.

- Isolated IgM cross-reactivity needs to be ruled out

- Use the right test at the right time.

The aim is to ensure that the test result adds content and not confusion to the clinical scenario and affect patient management.

\section{References}

1. Halstead SB. Dengue. Lancet 2007;370(9599):1644-1652. DOI: 10.1016/ S0140-6736(07)61687-0.

2. Khetarpal N, Khanna I. Dengue fever: causes, complications, and vaccine strategies. J Immunol Res 2016;2016:6803098.

3. Hasan S, Jamdar SF, Alalowi M, et al. Dengue virus: a global human threat: review of literature. J Int Soc Prev Community Dent 2016;6(1):16. DOI: $10.4103 / 2231-0762.175416$.

4. Peeling RW, Artsob H, Pelegrino JL, et al. Evaluation of diagnostic tests: dengue. Nat Rev Microbiol 2010;8(S12):S30-S38. DOI: 10.1038/ nrmicro2459.

5. Chan $\mathrm{HBY}$, How $\mathrm{CH}, \mathrm{Ng} \mathrm{CW}$. Definitive tests for dengue fever: When and which should I use? Singapore Med J 2017;58(11):632-635. DOI: 10.11622/smedj.2017100.

6. Atif $M$, Raheel $U$, Imran $M$, et al. Dengue virus: host-pathogen interactions and emerging role of DNA vaccines. J Hum Virol Retrovirol 2016;3(3):00091.

7. Changal $\mathrm{KH}$, Raina $\mathrm{AH}$, Raina $\mathrm{A}$, et al. Differentiating secondary from primary dengue using IgG to IgM ratio in early dengue: an observational hospital based clinico-serological study from north india. BMC Infect Dis 2016;16(1):715. DOI: 10.1186/s12879-0162053-6.

8. Raafat N, Blacksell SD, Maude RJ. A review of dengue diagnostics and implications for surveillance and control. Trans R Soc Trop Med Hyg 2019;113(11):653-660. DOI: 10.1093/trstmh/trz068. 